\title{
De espaço e território, estrutura e processo
}

\section{Of space and territory, structure and process}

\author{
Haesbaert, Rogério (2O I I), EL MITO DE LA DESTERRITORIALIZACIÓN: \\ DEL FIN DE LOS TERRITORIOS A LA MULTITERRITORIALIDAD, SiglO XXI, \\ MÉXICO, 328 PP., ISBN: 978-607-0308-I
}

Foi com enorme satisfação que recebi o convite do sociólogo mexicano Gilberto Giménez para o lançamento de meu livro El mito de la desterritorialización junto ao grupo editorial Siglo XxI, na cidade do México, em setembro de 2012. Ao contrário dos lançamentos eminentemente festivos, sem debate, promoveu-se ali uma espécie de mesa-redonda com a apresentação do livro pelo próprio Gilberto e as geógrafas Verónica Ibarra e Blanca Ramírez.

Blanca intitulou muito bem sua fala "Da elegia ao espaço à do territorio" -elegia como um canto fúnebre, que se aplicaria ora ao espaço, ora ao território, demonstrando assim o grande imbroglio que se cria ao decretarmos o seu "fim"-. Meu livro propóe esse debate que não estava ainda explicitamente colocado ou, pelo menos, nos termos e na dimensão com que o formulo.

Blanca Ramírez foi incisiva em algumas críticas e elas me permitem esclarecer alguns pontos. Espero demonstrar que todas ou a maior parte de suas consideraçôes, se não estão contempladas no próprio livro, cuja tradução em espanhol é reprodução fiel da edição brasileira de 2004, já foram retrabalhadas em artigos publicados ao longo dos oito anos que desde aí se passaram. Lamento, por isso, que não tenhamos tido a oportunidade de intercambiar esses trabalhos ou mesmo de discutir essas ideias, desdobradas nas três conferências que realizei durante a estada no México.

Duas consideraçóes mais amplas são feitas por Blanca: uma, relativa à (in)distinção entre espaço e território, outra, sobre o caráter estruturalista da análise. É curioso como o livro já foi visto, ao mesmo tempo, como "pós-moderno" ou "pós-estruturalista" e como uma crítica à pósmodernidade (Vasconcellos, 2005). ${ }^{1}$ Isso revela a dificuldade de, com um único termo, genericamente, apreender a obra de um autor.

Em primeiro lugar, gostaria de esclarecer que o livro de modo algum afirma que a falta de clareza do conceito de território está ligada apenas ao debate proposto sobre desterritorialização. $\mathrm{O}$ capítulo dois deixa

\footnotetext{
${ }^{1}$ Sobre minha posição nesse debate entre modernidade e pós-modernidade ver especialmente “Questôes sobre a (pós) modernidade” (Haesbaert, 2002 [1997]).
} 
muito claro o imenso conjunto de posiçóes epistemológicas que fazem do território um dos conceitos mais pol(iss)êmicos e cujo debate vai muito além daquele travado entre os autores que, mais recentemente, focalizam a "desterritorialização". Muitos dos autores ali analisados sequer fazem uso do termo "desterritorialização", e nem por isso foram desconsiderados. É destacado o papel justamente de dois autores, Claude Raffestin (1993 [1980]) e Robert Sack, que são os mais representativos das duas correntes, francesa e anglo-saxônica que, Blanca sugere, centralizam suas noções de território em torno do Estado nação (mas tanto Raffestin quanto Sack tem concepçóes muito mais amplas).

Com relação aos conceitos de espaço e território, esta é uma questão que desde antes da publicaçáo do livro me era colocada. Inicialmente, como para muitos geógrafos, minha referência era Raffestin, para quem o espaço é a "prisão original", "matéria prima" sobre a qual atuam os processos sociais de apropriaçáo que a transformam na "prisão" que os homens constroem para si. Em trabalho mais recente, entretanto, eu comento:

\begin{abstract}
Ao afirmar que "o território se apoia no espaço, mas não é o espaço; é uma produção a partir do espaço" (1993:144), Raffestin acaba se confundindo na própria alusão que faz a Lefebvre, como se este também partilhasse dessa 'passagem' do espaço ao território. Ao contrário, para Lefebvre (1986), o espaço também - e sobretudo - é produzido socialmente, não se tratando em hipótese alguma de um "a priori" (uma espécie de "primeira natureza" [para Raffestin; categoria a priori de nossa intuição, para Kant]) sobre o qual reproduzimos nosso trabalho e exercemos poder (Haesbaert, 2009:104).
\end{abstract}

É importante relembrar que os conceitos não são entidades estáticas e separáveis da "familia" conceitual construída dentro da filiação filosófica de um autor. A própria realidade a que eles se referem (e que, de alguma maneira, também ajudam a construir), numa visão relacional, não é constituída por entidades estanques. É por isso que, na constelação conceitual de alguns autores, território adquire uma conotação central, a ponto de se confundir com a própria noção de espaço (como ocorre explicitamente em Milton Santos), enquanto para outros ele pode se transformar num conceito mais restrito e quase secundário. Além disso, não devemos nos prender tanto ao formalismo das nomenclaturas (palavras), mas, sobretudo, aos efetivos conteúdos conceituais que elas propóem. ${ }^{2}$

No livro, cito um autor como Moraes (nota na pág. 32) que propóe tratar espaço como categoria, em sentido mais amplo e abstrato, e terri-

\footnotetext{
${ }^{2}$ A propósito, ver nossa discussão sobre a relação de proximidade e mesmo, muitas vezes, de equivalência entre os conceitos de território na Geografia latino-americana e lugar na Geografia anglo-saxônica (Haesbaert, 2013).
} 
tório como "conceito preciso". No entanto, dada a fundamentação lefebvreana que inspira meu trabalho, "espaço", enquanto também (como o território) uma produção social, não pode ser reduzido a uma "categoria de análise" (mesmo porque permeia intensamente nossa vida, ainda, como “categoria da prática”) - o que poderia implicar num questionável retorno a Kant e sua concepção de espaço como categoria a priori da consciência.

A partir de nossa filiação teórica lefebvreana na definição de espaço, alguns poderiam entendê-la como "indiferenciada” em relação ao conceito de território (termo que, de fato, Lefebvre [1984] muito raramente utiliza). No entanto, deixamos também muito explícito que os processos de dominação (mais concreto-funcional) e de apropriação (mais simbólica), tal como definidos por Lefebvre, são apreendidos na perspectiva do poder que eles implicam, seja do poder em sua dimensão mais estritamente política, seja o poder em sua perspectiva econômica ou simbólica. Daí afirmarmos:

... não se trata, evidentemente, de distinguir de maneira [...] rígida espaço de território. Embora não equivalentes, como se referiu Raffestin, espaço e território nunca poderão ser separados, já que sem espaço não há território - o espaço não como um outro tipo de "recorte" ou "objeto empírico" (tal como na noção de "matéria-prima preexistente" ainda não apropriada [em Raffestin]) mas, num âmbito mais epistemológico, como um outro nível de reflexão ou um "outro olhar", mais amplo [...], e cuja "problemática” específica se confunde com uma das dimensóes, fundamentais, da sociedade, a dimensão espacial. Ao território caberia, dentro desta dimensão, um foco centralizado na espacialidade das relaçóes de poder (Haesbaert, 2009:105).

A grande questão que se coloca, a partir daí, é com que concepção de poder iremos trabalhar para definir território. A característica deste texto não permite o devido aprofundamento, mas de maneira sintética, fica claro em nossa perspectiva que a concepção de poder com que trabalhamos não tem absolutamente nada de "estruturalista" - e aqui associamos a primeira com a segunda grande questão colocada por Ramírez. A concepçáo de poder que nos leva a uma definiçáo efetivamente relacional e não estruturalista de território é aquela que, inspirada em um autor como Foucault (e seguindo Raffestin, como detalhado na página 71 da versão em espanhol de nosso livro), vê em toda relação social - e assim, em toda relação de construçáo do espaço - uma relação de poder, ou seja, a "dimensão territorial" está sempre presente em todo processo de construção do espaço enquanto espaço social.

A posição de Ramírez pode, implícitamente, induzir a própria perspectiva (estruturalista) que ela condena pois, no nosso ponto de vista, o problema ocorre justamente quando não percebemos o território enquanto dimensáo do espaço (de todo e qualquer espaço) e separamos (como faz 
Raffestin) espaço de território (ainda que em termos de um antes, "matéria-prima", e um depois, "espaço socialmente apropriado"). Nossa concepção relacional de poder - o poder não apenas como mediador, mas como constituinte, indissociável, de qualquer relação social - pretende ir um pouco além de Foucault e destaca também sua perspectiva simbólica que, sob nosso capitalismo "de espetáculo" (parafraseando Guy Débord), torna-se cada vez mais relevante.

Nesse sentido, para além do poder simbólico no sentido de Bourdieu (referido em nosso livro), trabalhamos no cruzamento entre Foucault e $\mathrm{Gramsci}^{3}$ - e, antes que nos questionem, afirmamos que não há nada de incongruente nessa associação, principalmente se lembrarmos a contribuição de autores como Edward Saïd e Stuart Hall. Assim, essa concepção de poder é claramente anti-estruturalista e parte do pressuposto de que somente é possível compreender o poder na indissociabilidade entre suas dimensóes mais estritamente políticas (na figura do Estado, por exemplo), econômicas e simbólicas. A alegação de que não "voltamos a reunir" as esferas econômica, política e cultural perde sentido quando se percebe de que concepção de poder partimos para definir o território e, mais ainda, como veremos mais adiante, quando enfatizamos a perspectiva social do território (e da desterritorialização) na parte final de nosso trabalho.

Discordamos, portanto, da ênfase dada ao estruturalismo de nossa análise - especialmente porque tivemos a preocupação, todo o tempo, de destacar que não há um "a priori” estruturante (seja ele o econômico, o político ou o cultural), como a própria autora reconhece ao final do texto, e que não há uma "estabilidade" que se impóe sobre o movimento, os processos, a transformação (nossa definição de território inclui também, e muitas vezes sobretudo o movimento, o controle em rede), e que se trata sempre de "dimensóes", nunca de "estruturas" - palavra que só aparece, e sempre para caracterizar posiçóes ou formular críticas, até a página 141 das 320 do livro. O controle territorial, ao contrário do que afirma Ramírez, também é discutido a partir da perspectiva do Estado - ao começar pelo debate com o principal autor que defende a perspec-

\footnotetext{
${ }^{3}$ Não é demais lembrar que Gramsci foi o autor marxista que, superando uma leitura estruturalista que delegava ao econômico, a priori, a base ("estrutura") da organização social, indicou a relevância da cultura, no mesmo patamar, para a construção do poder. Daí seu conceito de hegemonia implicar não só o poder em seu sentido coercitivo, mas também de consenso, de criaçáo de uma coesão simbólica (ou, em outros termos, "ideológica”) capaz, por exemplo, de amalgamar uma sociedade de classes.

${ }^{4}$ Fizemos questão de deixar isso muito claro: "Distinguir entre una desterritorialización de 'matriz' predominantemente económica, otra de matriz política y una tercera de matriz cultural no significa adoptar una posición estructuralista que diferencia de forma clara esos componentes, en realidad dimensiones o perspectivas de lo social, identificadas así fundamentalmente porque los discursos sobre la desterritorialización en general asumen esa separación” (Haesbaert, 2011a:141).
} 
tiva do controle do acesso, Robert Sack, uma parte do debate com Deleuze e Guattari e nosso exemplo relativo às migraçóes. ${ }^{5}$

No que se refere à relação entre território e rede, não é demais lembrar que defendemos exatamente o contrário da dicotomia representada na página 239 (dicotomia amplamente criticada no texto) - todo território é constituído de redes, e muitas vezes ela é seu elemento preponderante. $\mathrm{Na}$ verdade trabalhamos não com um binômio (território e rede), mas com uma tríade, ao acrescentarmos aí a condição de "aglomerado", responsável por uma certa ilógica ou desordem desterritorializadora que, ao lado das lógicas zonal e reticular, é constituinte de toda composição espaço-temporal.

Por outro lado, é preciso reconhecer que outra característica fundamental de nosso trabalho também questiona o estruturalismo: a valorização da multiplicidade, revelada na própria ideia de multiterritorialidade. Não há em nosso livro a pretensão (como fazem muitos estruturalistas) de desenhar uma grande teoria ou sistema que subjugue a enorme diversidade de situaçóes em que os processos de des-territorialização são constantemente redefinidos. Por mais que o Estado nação e o grande capital transnacional tentem, não conseguem subjugar a multiplicidade de formas de resistência à territorialização capitalista-estatal hegemónica.

Além dessa superação dos a prioris e da valorização dos processos e da multiplicidade, trabalhamos com a indissociabilidade entre territórios-zona, territórios-rede e aglomerados, vendo o território muito mais a partir de uma dinâmica de des-re-territorialização, sempre contraditória e/ou ambivalente, do que como uma entidade estável e bem definida. Daí que "el territorio, construido a partir de una perspectiva relacional del espacio se concibe como totalmente inmerso dentro de relaciones sociohistóricas o, de modo más estricto, de poder" (p. 69), com "una enorme variación histórica" y también "geográfica" (p. 83). Além disso, nossa análise, ao contrário da maior parte das abordagens estruturalistas, está centrada nos sujeitos, pois "implica identificar y colocar en primer plano a los sujetos de la des-reterritorialización, o sea, quién desterritorializa a quién y con qué objetivos." (p. 214).

Assim, "la casi ausente discusión estrictamente social del tema”, a que se refere Ramírez, perde sentido quando se observa que a grande contribuição na análise específica da desterritorialização é justamente o debate sobre sua dimensão social e que, analisada ao final do texto, acaba por

\footnotetext{
${ }_{5}^{5}$ Sobre o papel do Estado nos processos de des-territorialização veja-se o debate sobre a relação espaço-tempo na pós-modernidade (cap. 4), a relação Estado-economia e Estado-cultura (no cap. 5, mostrando que, mesmo diferenciando dimensóes, não o tratamos de forma isolada), a relação entre território-zona e território-rede (ítem 7.1) e o exemplo "multiterritorial" da Al Qaeda. Sobre o papel do Estado em relação às migraçôes, v. especialmente p. 204-205. Desenvolvemos mais especificamente a relação Estado-desterritorializaçâo em Haesbaert, 2011 b.
} 
integrar todas as dimensóes trabalhadas, a partir da ótica de uma desterritorialização que afeta sobretudo os grupos subalternos:

De modo sorprendente, como lo hemos señalado en otros momentos, la perspectiva más específicamente social que el debate sobre la desterritorialización debería priorizar, casi no se ha abordado [pelos diferentes autores que utilizam o termo]. Es probable que esta omisión, vinculada a la lectura crítica que la questión en general implica, vinculada a su vez a la creciente exclusión (o inclusión precaria) promovida por el capitalismo contemporáneo, debe asociarse al hecho de que esos discursos están moldeados desde los países centrales. (p. 258) [...] la imbricación entre exclusión social y desterritorialización parte del presupuesto de que ambas nociones incorporan siempre un carácter social multidimensional, dinámico y que debe ser contextualizado de forma geográfica e histórica (Haesbaert, 2011a: 259).

Desenvolvemos, assim, uma reflexão sobre a desterritorialização como precarização territorial, inspirados na precarização social ou “inclusão precária” proposta pelo sociólogo José de Souza Martins. É justamente para a condição dos mais precarizados - ou dos "precariamente territorializados" - que desterritorialização se torna um conceito mais consistente. ${ }^{6}$

Também é totalmente contrária a nossa análise a afirmação de que a "visión de tres áreas en la multiterritorialidad [territórios-zona, territóriosrede e aglomerados, como se eles pudessem ser dissociados] que parecería que siguen procesos autónomos que no tienen que ver unos con otros y que hasta persiguen trayectorias autónomas”, especialmente quando afirmamos que:

... no se trata de concepciones contrapuestas y estancas. La relación de territorioszona, territorios-red y aglomerados con los procesos de desterritorialización y territorialización es ambivalente, e incluso [se] puede pasar de un extremo a otro: los niveles más fuertes de desterrritorialización, en medio de procesos de violenta inseguridad y exclusión social, pueden dar origen a los territorialismos más arraigados... (p. 254).

Trata-se sempre, nunca é demais lembrar, de "i-lógicas" concomitantes, separáveis apenas enquanto "tipos ideais" em termos analíticos, como bem ressaltamos na página 253. As concepçôes de território-zona, território-rede e aglomerado só podem ser lidas dentro do que denominamos distintas lógicas de construção do espaço: a lógica zonal (onde predomina o controle de áreas, como na lógica territorial dominante entre os Estados

\footnotetext{
${ }^{6}$ Sem ignorar, é claro, que, num sentido amplo, o movimento de desterritorialização, sem ser positivo ou negativo em si mesmo, equivale a todo processo de saída ou de destruiçáo de um território - para a reconstruçáo de outro, já que ninguém vive sem o controle de um espaço, por mais instável e precário que ele seja.
} 
naçôes), a lógica reticular (onde predomina o controle de redes, como na lógica territorial dominante entre as grandes empresas transnacionais) e a i-lógica dos aglomerados - capaz de dar conta dos processos desordenadores e "descontrolados", presentes "em maior ou menor grau em todos os espaços do nosso tempo" (p. 278).

A esse respeito, cabe ainda esclarecer que a reunião dessas três modalidades ou lógicas de des-territorialização não é sinónimo de "multiterritorialidade". Há diversos modos de experimentar, concomitantemente, múltiplos territórios, desde a multiterritorialidade "zonal" mais simples resultante da reunião de territórios-zona sobrepostos (como na lógica estatal "tradicional" que vai do municipio ao Estado nação - e para além dele, no caso da União Europeia), até a multiterritorialidade realizada via aparato técnico-informacional que permite a intervenção em território alheio sem deslocamente físico.

Quanto ao argumento de que autores de diferentes posiçóes teóricas se póem a dialogar no texto, isso ocorre, mas sempre com plena consciência e explicitação de suas distintas posições, inclusive político-ideológicas, já que enfatizo desde o início a filiação do discurso sobre a desterritorialização com o discurso neoliberal (especialmente aquele associado ao "fim do Estado" ou ao "fim das fronteiras" - para o grande capital). Aliás, uma das principais contribuiçóes de nosso trabalho consiste em distinguir as diversas correntes filosóficas que envolvem cada um dos principais autores que propóem concepçóes de território, desde as mais materialistas até as mais idealistas (cap. 2). O único caso apontado explicitamente por Ramírez de incongruência entre a posição teórica de dois autores se refere ao diálogo entre Harvey e Giddens, e isso exige uma discussão mais aprofundada.

Em primeiro lugar, náo vejo porque náo colocar dois autores a dialogar quando o que está em jogo é a forma com que leem a mesma questão: a relação espaço-tempo sob uma condição social dita "pós-moderna". $\mathrm{O}$ que não significa, é muito importante afirmar, que eu tenha considerado os dois autores "pós-modernos", como indica Ramírez. Ao contrário, como se pode ver claramente no quadro da página 119, ambos são considerados "modernos". Por outro lado, a diferenciação proposta pela autora para caracterizar Harvey como "pós-marxista" e Giddens como "moderno" é problemática - como se Harvey não fosse, também, um autor "moderno".

Como os próprios termos "estruturalismo" e "pós-estruturalismo", trata-se aqui de uma distinção que não é capaz de abarcar a complexidade de influências que marca a singular obra desses autores. Primeiro, porque Harvey, no meu ponto de vista, mesmo tendo escrito seu famoso livro "A condição pós-moderna", continua sendo um autor moderno, e 
até hoje seus livros são marcados, sobretudo, pela leitura materialista histórica e dialética (um discurso que marcou profundamente o "polo crítico" da modernidade). Ele jamais se "pós-marxizou", se pudéssemos utilizar essa expressão. Um "neo" marxismo, talvez, mas nunca sua superação. Assim como Giddens nunca deixou, também, de ser "moderno", mas numa condição distinta de Harvey, e que tentamos identificar no quadro da página 119 de nosso livro. ${ }^{7}$

Em relação à concepção de espaço e tempo, que é a que envolve mais diretamente a nossa reflexão no livro, Harvey e Giddens não têm tantas divergências, até porque Giddens foi um dos autores que mais enfatizou os processos e a ação, criticando justamente o estruturalismo ao propor sua teoria da estruturação, que busca superar o dualismo entre agenciamento e estrutura. A grande diferença, é claro, está no peso dado ao caráter conflitivo e às contradiçóes sociais em cada perspectiva. Mas se até mesmo autores marxistas, como Derek Gregory, já promoveram antes esse diálogo, considero que estou bem acompanhado. ${ }^{8}$

Tão importante quanto esse elo (ainda que bastante relativo) entre a teoria da estruturação e o marxismo renovado de Harvey é a aguçada sensibilidade de Giddens para com o espaço, e foi, sobretudo, aí que busquei esse diálogo. Gregory (1996) desenha inclusive um esquema (p. 112) em que aparece, numa direção, o "distanciamento tempo-espaço" (de Giddens) e, no sentido contrário, a "compressão tempo-espaço" (de Harvey), identificando como elemento comum entre os dois processos o "desentranhamento" entre "lugar" - tido ali como o campo da proximidade e dos contatos face-a-face (praticamente sinônimo de local) - e "espaço" - este num sentido mais amplo e cada vez mais global. Embora o autor pressuponha uma distinção polêmica entre espaço e lugar, ele realiza, em abordagem semelhante, a mesma relação que problematizei entre o "alongamento" ou distanciamento espaço-temporal de Giddens e a compressão espaço-tempo de Harvey, demonstrando assim, claramente, a proximidade de suas reflexóes sobre a nova configuração do espaço contemporâneo.

\footnotetext{
${ }^{7}$ Uma melhor explanação desse quadro pode ser vista em Haesbaert, 2002 (capítulo "Questōes sobre a (pós) modernidade").

${ }^{8}$ Para Gregory "o quanto" o projeto particular de Giddens "se afastou realmente do materialismo histórico ainda é assunto de debate", pois "Giddens não só reafirmou muitas das principais caracterizaçôes que Marx fez do capitalismo (incluindo, ocasionalmente, a teoria do valor trabalho), mas alguns críticos insistem que muitas de suas principais proposiçóes, que, supostamente, avançariam em outras direçôes radicais, foram, na verdade, antecipadas de diferentes maneiras por Marx e pelo desenvolvimento de outras tradiçóes do marxismo ocidental. [...] sua reformulaçáo da teoria social não é apenas uma crítica do materialismo histórico [...], afirma ele, mas também uma 'desconstrução' do materialismo histórico e os que o endossaram, na Geografia, conservaram uma filiaçấo mais próxima com o marxismo ocidental do que o próprio Giddens se permite" (Gregory, 1996: 108).
} 
Para finalizar, gostaria de destacar um trecho mais longo do próprio livro que, penso, desfaz qualquer malentendido a respeito da abordagem não-dicotômica e não-estruturalista que defendemos e que, centrada nos sujeitos sociais que estão em jogo (e não em "estruturas" ou "sistemas"), ao mesmo tempo não dissocia nem trata de modo indiferenciado os movimentos de territorialização e desterritorialização, amplamente distintos conforme os grupos ou classes sociais e os contextos geo-históricos a que se referem:

... si territorializarse implica siempre una relación de poder, concreta y simbólica a la vez, $[\ldots]$ es evidente que, como toda relación de poder, la territorialización se distribuye de forma desigual entre los sujetos y clases sociales, y en consecuencia, hay también ganadores y perdedores, controladores y controlados, territorializados que desterritorializan mediante una reterritorialización bajo su comando y desterritorializados [nunca de forma "total" (p. 258)] en busca de otra reterritorialización, de resistencia y, por lo tanto, diferente de la impuesta por sus desterritorializadores. [muitas vezes a distinçáo entre desterritorialização e reterritorialização, em função dos sujeitos em jogo, é também uma questão de escala: o que aparece como desterritorialização em uma escala pode significar reterritorialização em outra].

Esta constatación, más que un mero juego de palabras, es de enorme importancia, ya que implica identificar y colocar en primer plano a los sujetos de la des-reterritorialización, o sea, quién desterritorializa a quién y con qué objetivos. Permite también percibir el sentido relacional de dichos procesos, desarrollados en tramas múltiples en las que se conjugan de manera permanente distintos puntos de vista y acciones que promueven lo que podemos llamar territorializaciones desterritorializantes y desterritorializaciones reterritorializadoras. (p. 214)

Agradeço a Blanca Ramírez pela oportunidade de esclarecer e/ou retrabalhar muitos pontos. Como o objetivo principal deste intercâmbio é o debate, ele com certeza alimentará, em outros, novas questóes, e esta é a única forma de se fazer ciência -retomar e reavaliar constantemente nossos pressupostos - sempre com a máxima precaução para evitar rotulaçóes e/ou posiçóes simplificadoras, percebendo os conceitos, mais do que instrumentos "reveladores", como armas para repensar e transformar o mundo.

\section{Bibliografia}

Haesbaert, Rogério (2013), "Global sense of place and multi-territoriality: notes for dialogue from a 'peripheral' point of view" em: Featherstone, D. e Painter, J. (org.) Spatial Politics: Essays for Doreen Massey, Wiley-Blackwell, Chichester, pp. 146-157. 
Haesbaert, Rogério (2011a), El mito de la desterritorialización, Siglo XXI, México.

Haesbaert, Rogério (2011b), "O território e a nova des-territorialização do Estado", em: Dias, L. e Ferrari, M. (org.) Territorialidades humanas e redes sociais, Insular, Florianópolis, pp. 19-37.

Haesbaert, Rogério (2009), "Dilema de conceitos: espaço-território e contenção territorial”, em: Saquet, M. e Sposito, E. (org.) Territórios e territorialidades: teorias, processos e conflitos, Expressão Popular, São Paulo, pp. 95-120.

Haesbaert, Rogério (2002), Territórios Alternativos, Contexto, São Paulo.

Gregory, D. (1996), “Teoria social e Geografia humana” em: Gregory, D. et al. (org.) Geografia humana: sociedade, espaço e ciência social, Jorge Zahar, Rio de Janeiro, pp. 90-122.

Lefebvre, H. (1984 [1974]), La production de l'espace, Anthropos, París.

Raffestin, C. (1993 [1980]), Por uma geografia do poder, Ática, São Paulo.

Vasconcellos, G. (2005), “Autor põe geografia da pós-modernidade em questão", http://www1.folha.uol.com.br, Folha de São Paulo, 14 abril, São Paulo.

Recibida: 18 de febrero de 2013. Aceptada: 1 de abril de 2013.

Rogério Haesbaert Universidade Federal Fluminense Correo-e: riocult@yahoo.com

Rogério Haesbaert. Doutor em geografia humana pela Universidade de Sâo Paulo, com doutorado "sandwich" no Instituto de Estudos Políticos (IEP) de Paris e pós-doutorado na Open University, Milton Keynes, Inglaterra, é professor do Departamento de Geografia e do Programa de Pós-Graduaçáo em Geografia da Universidade Federal Fluminense, Niterói, Rio de Janeiro, Brasil, onde dirige o Núcleo de Estudos sobre Regionalização e Globalização (Nureg). É pesquisador nível 1 do Conselho Nacional de Desenvolvimento Científico e Tecnológico (CNPq) e 
membro fundador da revista GEOgraphia. Entre seus livros destacam-se RS: Latifúndio e Identidade Regional, Marcado Aberto, Porto Alegre (1988); Des-territorialização e Identidade: a "rede gaúcha" no Nordeste, Eduff Niterói (1997); Territórios Alternativos, Contexto, São Paulo, (2002), O Mito da Desterritorialização: do 'fim dos territórios' à multiterritorialidade, Bertrand Brasil, Rio de Janeiro, (2004) e Regional-Global: dilemas da regiāo e da regionalização na Geografia contemporânea, Bertrand Brasil, Rio de Janeiro (2010). 